\title{
DIREITOS HUMANOS, DESENVOLVIMENTO SUSTENTÁVEL E SUSTENTABILIDADE
}

\section{HUMAN RIGHTS, SUSTAINABLE DEVELOPMENT AND SUSTAINABILITY}

\begin{abstract}
DENIVAL FRANCISCO DA SILVA
Doutorando em Ciência Jurídica pela Universidade do Vale do Itajaí - UNIVALI -, SC. Mestre em Direito pela Universidade Federal de Pernambuco - UFPE -, PE. Especialista em Direito Público pelo Centro Universitário do Distrito Federal - UDF. Juiz de Direito da Comarca de Goiânia, GO. denivalfsilva@gmail.com
\end{abstract}

LUIZ GONZAGA SILVA ADOLFO Advogado, Doutor em Direito pela Universidade do Vale do Rio dos Sinos - UNISINOS -, RS. Presidente da Comissão Especial de Propriedade Intelectual da OAB, RS, na gestão 2010/2012. Membro da Associação Portuguesa de Direito Intelectual - APDI. Professor do PPG em Direito da Universidade de Santa Cruz do Sul - UNISC -, RS. Professor do Curso de Direito da Universidade Luterana do Brasil - ULBRA -, RS. gonzagaadolfo@yahoo.com.br

SONIA APAREIDA DE CARVALHO

Doutoranda em Ciência Jurídica pela Universidade do Vale do Itajaí - UNIVALI -, SC. Mestra em Direito pela Universidade de Santa Cruz do Sul - UNISC -, RS. Especialista em Direito do Trabalho pela Universidade Castelo Branco - UCB -, RJ. Especialista em Direito Ambiental pela Universidade Norte do Paraná - UNOPAR -, PR. Especialista em Direito Previdenciário pela Universidade Norte do Paraná - UNOPAR -, PR. sonia.adv.2008@hotmail.com

\section{RESUMO}

Este artigo trata da relação intrínseca entre os direitos humanos, o desenvolvimento sustentável e a sustentabilidade. Seu objetivo geral consiste em analisar o modelo de desenvolvimento implementado e a necessária proteção e preservação do meio ambiente ligado à defesa dos direitos humanos. Os objetivos específicos pretendem investigar a distinção dos termos sustentabilidade e desenvolvimento sustentável, como a concretização do direito à sustentabilidade, os critérios e as dimensões da sustentabilidade; pesquisar o reconhecimento de proteção e de efetivação do direito humano ao meio ambiente, como a relação entre os direitos humanos, o desenvolvimento sustentável e a sustentabilidade. 0 artigo propõe-se, ainda, a questionar a transformação do atual paradigma de desenvolvimento e sustentabilidade adotado, intimamente regido pelo padrão neoliberal. Esse questionamento busca demonstrar o caminho para alcançar a sustentabilidade, simultaneamente, com destaque nas questões ambientais e na proteção dos direitos humanos, para garantir à humanidade um futuro com igualdade e justiça social. 0 método de procedimento utilizado no artigo consiste na apreciação e interpretação da matéria e o método de pesquisa usado incide na elaboração, por meio de análise bibliográfica, utilizando-se das referências citadas.

Palavras-chave: Direitos Humanos; Desenvolvimento Sustentável; Sustentabilidade.

\begin{abstract}
This article deals with the intrinsic relationship between human rights, sustainable development and sustainability. Its overall objective is to analyze the development model implemented and the necessary protection and preservation of the environment related to human rights. The specific objectives aim to investigate the distinction of the terms sustainability and sustainable development, as the realization of the right to sustainability criteria and dimensions of sustainability; find the recognition and effective protection of the human right to the environment, such as the relationship between human rights, sustainable development and sustainability. The paper also proposes to question the transformation of the current development paradigm and sustainability adopted, closely governed by the neoliberal pattern. This question seeks to demonstrate the way to achieve sustainability, while highlighting the environmental issues and the protection of human rights, to ensure humanity a future with equality and social justice. The method of procedure used in this paper consists in the examination and interpretation of matter and the research method used focuses on the design, through literature analysis, using the cited references.
\end{abstract}

Keywords: Human Rights; Sustainable Development; Sustainability. 


\section{SUMÁRIO}

INTRODUÇAO; 1 DISTINÇ̃̃O DA SUSTENTABILIDADE E DO DESENVOLVIMENTO SUSTENTÁVEL; 1.1 Os critérios da sustentabilidade; 1.2 As dimensões da sustentabilidade; 2 O RECONHECIMENTO DE PROTEÇÃO DO DIREITO HUMANO E A CONSOLIDAÇÃO DA SUSTENTABILIDADE; 3 A RELAÇÃO ENTRE OS DIREITOS HUMANOS, O MEIO AMBIENTE E O DESENVOLVIMENTO; 3.1 Dano ambiental: violação de direitos humanos; 4 CONCLUSÃO; 5 REFERÊNCIAS.

\section{INTRODUÇÃO}

Este artigo pretende debater a vinculação entre os direitos humanos, o desenvolvimento sustentável e a sustentabilidade como uma relação intrínseca e fundamental de interesse global, com repercussões nas esferas ecológica e/ou ambiental, social, econômica, cultural, jurídica e política.

Primeiramente, defende não haver distinção entre o que expressam os termos sustentabilidade e desenvolvimento sustentável. Mas, logo, passa a refletir sobre o fato de essa distinção ser necessária para identificar a importância e o significado de cada termo, na perspectiva de preservação do meio ambiente e da limitação no uso dos recursos naturais, associado ao necessário desenvolvimento não somente para um crescimento econômico, mas, sobretudo, preocupado com a defesa dos direitos humanos.

Em seguida, passa a considerar a concretização do direito à sustentabilidade como um princípio constitucional e o aponta como valor fundamental, voltado a determinar direta e imediatamente a responsabilidade do Estado e da sociedade pela realização do desenvolvimento. Para tanto, é necessário que ele seja socialmente inclusivo, durável e equânime, ético e eficiente, no intuito de assegurar, de modo preventivo e precavido, no presente e no futuro, o direito ao bem-estar de todos os indivíduos.

Posteriormente, o artigo avalia o reconhecimento de proteção e de efetivação do direito humano ao meio ambiente, como o direito fundamental de caráter explícito e implícito, que visa a amparar o ambiente e a dignidade humana. É importante salientar que, ao falar em dignidade humana, destaca a sua essência - atributo exclusivamente humano - como a garantia dos direitos fundamentais, de modo a assegurar não apenas o mínimo existencial, mas todas as liberdades e capacidades humanas. 
Finalmente, o artigo analisa a relação essencial entre os direitos humanos e o crescimento econômico e social, reconhecendo a necessidade de proteção do meio ambiente, de assegurar o desenvolvimento de forma sustentável e o pleno gozo de todos os direitos fundamentais, numa perspectiva global, de efetivo resguardo ao ser humano sem quaisquer distinções. 0 método de procedimento utilizado no artigo consiste na apreciação e interpretação da matéria e o método de pesquisa usado incide na elaboração, por meio de análise bibliográfica, utilizando-se das referências citadas.

Diante disso, questiona-se repensar o modelo econômico hegemônico, assentado no neoliberalismo que representa a plena liberdade para o exercício da atividade privada, centrada exclusivamente no lucro fácil e rápido, com o mínimo compromisso com os temas do meio ambiente e dos direitos humanos, devido às condicionantes impostas aos Estados, especialmente, aos subdesenvolvidos ou em desenvolvimento.

\section{DISTINÇÃO DA SUSTENTABILIDADE E DO DESENVOLVIMENTO SUSTENTÁVEL}

Atualmente, pensar no desenvolvimento exige o compromisso com a sustentabilidade, elemento essencial e obrigação atribuída a todos como forma de proteção do futuro das gerações e do Planeta. Não se trata de opção ideológica com a questão ecológica e/ou ambiental, mas de preocupação da atual sociedade que se globalizou e trouxe consequências drásticas com a expansão do processo do modelo de crescimento desenfreado e devastador, acima da capacidade de oferta de recursos naturais, de preservação, recuperação e regeneração do meio ambiente.

Inicialmente, os termos sustentabilidade e desenvolvimento sustentável, embora sejam distintos, direcionam-se para um único significado, uma vez que são complementares entre si. Pode-se afirmar que a sustentabilidade relaciona-se com o fim, enquanto o desenvolvimento sustentável liga-se com o meio.

O termo sustentabilidade refere-se a três dimensões distintas e complementares entre si - a ecológica, a social e a econômica -, porquanto se trata da reprodução e produção das sociedades humanas no conjunto da biosfera. 0 atual modelo de economia e de sociedade tem 
que respeitar a capacidade de reprodução da Terra e reconhecer que os seres vivos são dependentes da biosfera.

En el plano ecológico parece evidente considerar la inviabilidad de la vida humana y de las sociedades durante mucho tiempo si estas se desarrollan en contradicción con los límites y procesos que las sostienen. Somos seres ecodependientes y como tales vivimos y somos en la naturaleza. En la dimensión social, la sostenibilidad se relaciona con la capacidad de satisfacer las necesidades humanas de forma justa y con la condición de interdependencia que caracteriza a los seres humanos. ${ }^{1}$

As primeiras preocupações com a questão ambiental, na esfera global, deram-se a partir da década de 1970. Antes disso, a percepção com a questão ambiental era a de que as fontes naturais seriam recursos inesgotáveis, enquanto o crescimento econômico e o desenvolvimento deveriam propiciar riqueza e renda. 0 mundo estava no momento da guerra fria e do avanço tecnológico e científico; e o desenvolvimento econômico servia como forma de promoção para o modelo político dos dois blocos opostos - o capitalista e o socialista. Nesse período, não havia a distinção de que as questões ambientais não respeitavam ideologias e tampouco as fronteiras geográficas. Toda e qualquer proposição voltada para a necessidade de se estabelecerem políticas responsáveis, como a preservação do meio ambiente e a sustentabilidade, representava a tentativa de conter o desenvolvimento do bloco contrário.

Com as posições assumidas pelas lideranças desses blocos contraditórios - de um lado os Estados Unidos da América (EUA) e de outro a União Soviética (URSS) - direcionavam-se no sentido de reafirmação do poder, com controle político e econômico sobre o espaço territorial. Não havia a harmonia entre a ideia de desenvolvimento sustentável e sustentabilidade, prevalecia somente o desejo de desenvolvimento como um projeto rumo ao infinito. A sustentabilidade seria uma forma de restrição ao próprio desenvolvimento, porque não haveria forma de consegui-lo sem a exploração dos recursos naturais. Nesse momento, na perspectiva de que o desenvolvimento não seria viável, foi preciso limitar o uso dos recursos naturais.

Com o fim do período da guerra fria, no final da década de 1980, prevaleceu a hegemonia do modelo capitalista. Sem qualquer contraposição, nesse modelo econômico globalizado e focado na ideia neoliberal da mínima interferência do poder público na gestão dos

\footnotetext{
${ }^{1}$ RIECHMANN, Jorge; REYES, Luis González; HERRERO, Yayo; MADORRÁN, Carmen (orgs.). Qué hacemos hoy cuando nos encontramos frente a la amenaza de una crisis mayor que la económica: la ecológica. Madrid: Ediciones Akal, S. A., 2012, p. 35-36.
} 
setores privados e econômicos, acentuaram-se em excesso os problemas quanto à preservação ambiental, à conservação dos recursos naturais, bem como se expandiram as desigualdades sociais.

As produções das grandes empresas multinacionais para os países subdesenvolvidos ou em desenvolvimento fizeram aumentar os danos ambientais globais: foram retirados os problemas dos grandes centros, transferindo parte dos efeitos poluentes e degradantes para as populações mais pobres da periferia. Diante do modelo econômico hegemônico, num cenário em que se busca crescimento econômico a qualquer custo, ampliaram-se os problemas ambientais devido ao aumento das agressões aos ecossistemas e à exploração descontrolada dos recursos naturais, em especial, nos países subdesenvolvidos. Noutra medida, provocou o aumento das desigualdades sociais e o empobrecimento das populações, inclusive, com crises humanitárias.

Do distanciamento entre o crescimento econômico - com a preservação e a proteção ambiental - e a defesa dos direitos humanos, surgiu a percepção para um novo pensar do modelo de desenvolvimento sustentável, dando origem ao termo sustentabilidade. Nas palavras de Bachelet, ${ }^{2}$ a sustentabilidade "requer no mínimo a manutenção no tempo de um stock constante de capital natural, necessário às necessidades das futuras gerações para as quais as atuais reclamam o direito ao desenvolvimento", interligado aos direitos fundamentais da humanidade. Dessa forma, a sustentabilidade deverá ser construída a partir das dimensões ecológica, ambiental, social, econômica, cultural e tecnológica.

Para alcançar a sustentabilidade, é preciso buscar o modelo de desenvolvimento assentado em bases adequadas, com atenção às demandas sociais, políticas e econômicas, de forma equilibrada e sem violar os direitos humanos. Essa busca depende da atuação do poder público na definição de políticas e programas com o modelo de sustentabilidade e com o envolvimento de todos os atores sociais no compromisso com a questão ecológica e/ou ambiental.

Compete, ainda, ao setor público promover o indispensável respeito à diversidade política e cultural, como patrimônio imaterial dos povos e forma de autodeterminação. Ademais, é tarefa do Estado reconhecer que os desequilíbrios sociais são causados por fatores econômicos, como os problemas decorrentes, em especial, as desigualdades que provocam a carência da parcela da população sem meios e condições de sobrevivência.

${ }^{2}$ BACHELET, Michel. Ingerência ecológica: direito ambiental em questão. Tradução de Fernanda Oliveira. Lisboa: Instituto Piaget, 1995, p. 184. 
No que se refere ao setor privado, é preciso conter o avanço do desenvolvimento irresponsável, ligado ao modelo neoliberal do lucro fácil, de ganhos econômicos altamente desproporcionais $^{3}$ e benefícios políticos. É preciso atribuir não só ao Estado o dever de zelar pelos bens naturais, considerando ser obrigação de todos protegerem a natureza, criando a cultura da preservação e conservação, inclusive, como fonte de manutenção da atividade econômica, assegurando iguais recursos e bens para as futuras gerações.

Em síntese, “nem tudo está à venda” ou é passível de livre gozo. Essa é uma afirmação de Sachs ao destacar que o desenvolvimento sustentável deve corresponder ao “equilíbrio entre o mercado, o Estado e a sociedade civil, considerando as instituições externas ao mercado como necessárias para fiscalizar e corrigir seus excessos e deficiências". ${ }^{4}$ Desse modo, de um lado, o desenvolvimento sustentável é o caminho intermediário entre o crescimento com restrição na utilização e no manuseio dos recursos naturais e, de outro lado, o crescimento econômico sem nenhuma restrição. Nesse aspecto, não há a possibilidade de se obter o desenvolvimento sustentável num livre mercado, sequer num Estado controlador e conservador quanto ao uso dos bens naturais.

É imperativo rever e reverter o processo de exploração e utilização dos recursos naturais como condição básica de manutenção da própria vida e de habitação na Terra. Nesse sentido, não se trata mais de escolhas, mas de necessidade quanto à forma de uso e de acesso às fontes de recursos naturais.

Portanto, é fundamental equilibrar as posições, permitindo a interferência do poder público para regular e conter o crescimento descomprometido, como as questões globais que envolvem todo o ecossistema e os bens ambientais, incluindo a existência humana com dignidade, porém sem inviabilizar a própria atividade econômica.

\footnotetext{
3 "O desenvolvimento sustentável é, evidentemente, incompatível com o jogo sem restrições das forças de mercado. Os mercados são por demais míopes para transcender os curtos prazos e cegos para quaisquer considerações que não sejam lucros e a eficiência Smithiana de alocação de recursos". SACHS, Ignacy. Caminhos para o desenvolvimento sustentável. Organização de Paula Yone Stroh. Rio de Janeiro: Garamond, 2002, p. 55.

${ }^{4}$ KUTTNER, Robert apud SACHS, 2002, p. 56.
} 


\subsection{Os critérios da sustentabilidade}

Os critérios da sustentabilidade baseiam-se em vários eixos distintos. Como adverte Sachs, a sustentabilidade não se atrela exclusivamente à dimensão ambiental, vincula-se às dimensões social, econômica, ecológica, cultural, espacial ou territorial e política. ${ }^{5}$

A sustentabilidade social diz respeito ao equilíbrio na distribuição justa de rendas, a fim de propiciar melhoria da qualidade de vida da população e redução das diferenças sociais, de modo a assegurar condição de vida com dignidade, o que implica, também, no acesso aos recursos e serviços sociais. Sachs enfatiza que essa modalidade antecede todas as demais "por se destacar como a própria finalidade do desenvolvimento, sem contar a probabilidade de que um colapso social ocorra antes da catástrofe ambiental". ${ }^{6}$

A sustentabilidade econômica somente pode se garantir se houver o equilíbrio intersetorial, com capacitação e modernização dos instrumentos e processos de produção que assegurem tanto o desenvolvimento da economia interna como o da externa. Sachs adverte que, embora apareça como uma necessidade, de modo algum a sustentabilidade econômica é precondição para as demais. Para esse autor, os desequilíbrios econômicos estão atrelados aos desajustes sociais que, por sua vez, impactam a sustentabilidade ambiental. ${ }^{7}$

A sustentabilidade ecológica envolve o uso adequado das fontes de recursos naturais de modo a minimizar os impactos aos ecossistemas e, por consequência, à preservação da vida. Implica na necessidade de preservação do capital natural com o uso controlado dos recursos renováveis e restrição da utilização dos recursos não renováveis.

A sustentabilidade cultural implica no cumprimento da ideia de pluralismo, respeitando as diferenças e os valores culturais entre os povos, e exige ações ponderadas e respeitosas às tradições sem abdicar das inovações.

A sustentabilidade espacial ou territorial corresponde, no incentivo para ocorrência e preservação de equilíbrio entre os espaços rural e urbano, com atenção ao fenômeno migratório, à necessidade de desincentivo à concentração urbana e à remediação das áreas de enorme

\footnotetext{
${ }^{5}$ SACHS, Ignacy. Caminhos para o desenvolvimento sustentável. Tradução de José Lins Albuquerque Filho. Organização de Paula Yone Stroh. Rio de Janeiro: Garamond, 2009, p. 85.

${ }^{6}$ SACHS, 2009, p. 71.

${ }^{7}$ SACHS, 2009, p. 71.
} 
densidade demográfica, com planejamento de alocação industrial e manejo adequado e seguro das florestas e recursos naturais.

A sustentabilidade política compreende relações internas e externas, sempre numa perspectiva democrática para além da ideia de representação, periodicidade no poder e direito ao sufrágio, mas, sobretudo, abarcando efetivamente os direitos humanos. Nesse sentido, compete ao Estado assumir os compromissos determinados em torno da questão humanista, com a integração de todos os que apresentarem características sociais, reconhecendo no indivíduo a própria razão de ser.

$\mathrm{Na}$ esfera internacional, a sustentabilidade política visa a integrar o sistema de preservação de conflitos e guerras com empenho na promoção contínua da paz. Ainda, é necessária a atenção para que haja a redução das desigualdades, promovendo o desenvolvimento das regiões planetárias mais pobres, com autonomia no uso dos recursos, sem renunciar aos avanços produzidos pela ciência e pela tecnologia, bem como pelo desenvolvimento social e econômico. Essa postura não só condiz com a essência da defesa dos direitos humanos, interligados na ideia de sustentabilidade, como contribui para que haja a preservação de recursos naturais, da biodiversidade e de todo o meio ambiente do Planeta.

A sustentabilidade ambiental diz respeito à integração do ente humano no espaço geográfico, com a preservação e conservação dos ecossistemas naturais. No mesmo sentido, ocorre a preocupação com a vida digna das pessoas, com foco na erradicação da pobreza, nas desigualdades sociais e na exclusão social.

Conforme afirma Bosselmann, "os seres humanos valem muito mais do que o meio ambiente como objeto de proteção". Entretanto, não se pode atender às necessidades de uma existência com dignidade sem que haja "uma concepção compartilhada em comum de que o bem-estar humano depende do bem-estar de todo o mundo vivo". A vida humana, como de resto todo ser vivo no planeta, "reflete uma concepção comum de que o meio ambiente é indispensável". 8

Porquanto, esses são os principais critérios para um plano de sustentabilidade com destaque ao respeito e à prevalência dos direitos humanos. Nesse aspecto, há uma "simbiose" entre o desenvolvimento sustentável e a proteção aos direitos humanos. A preservação do meio

${ }^{8}$ BOSSELMANN, Klaus. Direitos humanos, meio ambiente e sustentabilidade. In: SARLET, Ingo Wolfgang (org.); KRELL, Andreas J. et al. Estado socioambiental e direitos fundamentais. Porto Alegre: Livraria do Advogado, 2010, p. 77. 
ambiente e a utilização racional de seus recursos condizem com a pauta de satisfação dos direitos básicos e essenciais do ser humano. ${ }^{9}$ Não é possível assegurar a dignidade humana onde as condições de desenvolvimento e de sustentabilidade sejam continuamente violentadas, em especial, quando essa agressão é voltada para a exploração desenfreada e irresponsável dos recursos naturais, patrimônio de toda a humanidade.

\subsection{As dimensões da sustentabilidade}

Para melhor compreender a sustentabilidade, é necessário percebê-la como um processo contínuo, aberto e interativo, que se conduz sobre as dimensões ética, social, ambiental, econômica, jurídica e política.

A sustentabilidade sob a dimensão ética consiste na conscientização de que vivemos num planeta habitado por uma infinidade de seres vivos, de modo que o espaço terrestre não pertence única e exclusivamente ao ente humano. A percepção ética permite compreender que, para além da ideia de "preservação ambiental e de uso cometido e responsável dos bens naturais, a sustentabilidade corresponde às relações entre o ente humano e todos os elementos que compõem o mundo a sua volta". ${ }^{10}$ Para um agir ético, não basta fomentar políticas e fazer a defesa consistente em prol do ser humano, se nesse discurso e agir houver menosprezo por outras formas de vida. 0 planeta é, por si, um organismo vivo que depende de todas as criaturas e vidas nele existentes.

A sustentabilidade sob a dimensão social reclama o desenvolvimento da igualdade intrageracional e intergeracional, assegurando a preservação ambiental, ecológica, cultural, com responsabilidade para o futuro das gerações. Essa é a dimensão em que o ser humano é colocado no centro das discussões e, por isso, é o lugar onde há uma ligação entre sustentabilidade e direitos humanos. Abrange o domínio de recursos para a concretização dos direitos

\footnotetext{
9 "O meio ambiente está vinculado de forma muito intensa e direta tanto com a dignidade humana como com a solidariedade. Afinal, a verdadeira justiça social e ambiental somente será alcançada com a concretização simultânea da dignidade humana e da solidariedade". CRUZ, Paulo Márcio; BODNAR, Zenildo. Globalização, transnacionalidade e sustentabilidade. Itajaí: Univali, 2012. E-book. Disponível em: <http://siaiapp28.univali.br/LstFree.aspx>. Acesso em: 10 jul. 2014, p. 130.

10 SOARES, Josemar. A dimensão ético-existencial da sustentabilidade. In: XXI Encontro Nacional do CONPEDI, 2012, Uberlândia. Anais do XXI Encontro Nacional do CONPEDI. Florianópolis: Fundação Boiteux, 2012, p. 5068-5108. Disponível em: <http://www.publicadireito.com.br/artigos/?cod=d523773c6b194f37>. Acesso em: 20 jul. 2014.
} 
fundamentais, garantindo o acesso de todos aos serviços públicos essenciais e condições dignas de existência com maior equidade, distribuição de renda e qualidade de vida.

A sustentabilidade sob a dimensão ambiental percebe que não pode haver qualidade de vida e dignidade em um ambiente degradado e que tende a sucumbir cada vez mais diante da ineficácia dos direitos fundamentais, tanto nas condições ambientais como na promoção humana. No que se refere à dimensão econômica, é indispensável à busca do equilíbrio e equidade com maior distribuição dos custos e benefícios diretos e indiretos do desenvolvimento.

Atinente às dimensões jurídica e política, há um compromisso imediato e vinculante a partir de princípios constitucionais, instituídos no texto de 1988 , nos artigos $1 .^{\circ}$ (quando trata como princípio fundamental da República Federativa do Brasil a dignidade humana e o pluralismo), $3 .^{\circ}$ (ao constituir como objetivo fundamental da República Federativa do Brasil a construção de uma sociedade livre, justa e solidária, o desenvolvimento nacional, a erradicação da pobreza, da marginalização e das desigualdades sociais e regionais), $4 .^{\circ}$ (ao estabelecer como princípios à prevalência dos direitos humanos, a autodeterminação dos povos, a defesa da paz, a cooperação entre os povos para o progresso da humanidade), $5 .^{\circ}$ e $6 .^{\circ}$, ao trazerem um enorme catálogo de direitos fundamentais.

O primado da sustentabilidade encontra amparo, ainda, na Constituição, nas disposições dos artigos 225 e 170, inciso VI, sem abandono a qualquer outra estipulada e descrita em documentos internacionais, à eficácia dos direitos fundamentais "e que faz desproporcional e antijurídica, precisamente em função do seu caráter normativo, toda e qualquer omissão causadora de injustos danos intrageracionais e intergeracionais". ${ }^{11}$

Do mesmo modo, adotadas essas dimensões, Leff salienta que "a sustentabilidade é uma maneira de repensar a produção e o processo econômico, de abrir o fluxo do tempo a partir da reconfiguração das identidades, rompendo o cerco do mundo e o fechamento da história impostos pela globalização econômica". ${ }^{12}$ E continua o autor afirmando que a sustentabilidade baseia-se nas estratégias de participação social, pois "a crise ambiental está mobilizando novos atores e interesses sociais para a reapropriação da natureza". ${ }^{13}$ Diante das estratégias de apropriação econômica da natureza e da cultura, emerge uma ética ambiental que propõe uma revalorização da vida do ser humano, pois “o princípio da sustentabilidade surge como uma

\footnotetext{
${ }^{11}$ FREITAS, Juarez. Sustentabilidade: direito ao futuro. 2. ed. Belo Horizonte: Fórum, 2012, p. 71.

12 LEFF, Enrique. Discursos sustentáveis. Tradução de Silvana Cobucci Leite. São Paulo: Cortez, 2010, p. 31.

${ }^{13}$ LEFF, 2010, p. 31.
} 
resposta à fratura da razão modernizadora e como uma condição para construir uma nova racionalidade produtiva, fundada no potencial ecológico e em novos sentidos de civilização a partir da diversidade cultural do gênero humano". ${ }^{14}$

Consequentemente, a sustentabilidade anuncia o limite da racionalidade econômica, proclamando os valores da vida, da justiça social e do compromisso com as gerações vindouras, almejando uma racionalidade ambiental. Retomando Leff, pode-se assegurar que a sustentabilidade mira no futuro de solidariedade que perpassa gerações e assume um compromisso com as posteriores. ${ }^{15}$ Concluindo suas argumentações, esse autor assevera que "a sustentabilidade aparece como uma necessidade de restabelecer o lugar da natureza na teoria econômica [...] internalizando condições ecológicas da produção que assegurem a sobrevivência e um futuro para a humanidade". ${ }^{16}$

Nessa mesma linha, Cruz e Bodnar defendem que "a sustentabilidade importa em transformação social, sendo conceito integrador e unificante, isso implica na celebração da unidade ser humano e natureza, na origem e no destino comum". ${ }^{17}$ Apreende-se que a sustentabilidade deve contribuir com os demais princípios constitucionais e que, movidos pelo impulso da sociedade civil, haverá de apontar o caminho para uma governança responsável com a preservação, a conservação dos recursos e bens naturais, assim como com uma organização social mais igualitária. ${ }^{18}$ A sustentabilidade é, juntamente com a ideia de governança, uma categoria em fase de consolidação que requer um agir construtivo de vários campos do saber humano.

Nesse sentido, Cruz e Bodnar assinalam que "a consolidação da sustentabilidade, enquanto princípio jurídico, é fundamental [...] para que seja garantida a justiça ambiental entre as gerações presentes e futuras". ${ }^{19}$ Enfatizam, também, esses autores a necessidade de se estabelecer uma ideia "de sustentabilidade global, baseada num paradigma de aproximação entre os povos e cultura", ${ }^{20}$ com o respeito ao pluralismo, às tradições e aos costumes,

${ }^{14}$ LEFF, Enrique. Saber ambiental: sustentabilidade, racionalidade, complexidade, poder. Tradução de Lúcia Mathilde Endlich Orth. 8. ed. Petrópolis: Vozes, 2011, p. 31.

${ }^{15}$ LEFF, 2011, p. 412.

${ }^{16}$ LEFF, 2011, p. 48.

17 CRUZ, Paulo Márcio; BODNAR, Zenildo (orgs.). Globalização, transnacionalidade e sustentabilidade. Itajaí: Univali, 2012. Disponível em: <http://www.univali.br/ppcj/ebook>. Acesso em: 5 maio. 2013, p. 51 .

${ }^{18}$ CRUZ; BODNAR, 2013, p. 52.

${ }^{19}$ CRUZ; BODNAR, 2013, p. 122.

${ }^{20}$ CRUZ; BODNAR, 2013, p. 119. 
integrados com o conhecimento científico e o desenvolvimento tecnológico, requisitos imprescindíveis para se pensar num futuro com justiça social.

\section{O RECONHECIMENTO DE PROTEÇÃO DO DIREITO HUMANO E A CONSOLIDAÇÃO DA SUSTENTABILIDADE}

Com o objetivo de efetivar o conceito de desenvolvimento sustentável, a Organização das Nações Unidas (ONU), por intermédio da Comissão Mundial sobre Meio Ambiente e Desenvolvimento, de 1987, apresentou o Relatório de Bruntland. Nesse Relatório, o conceito de desenvolvimento sustentável define-se como "a capacidade humana de assegurar que o desenvolvimento atenda às necessidades do presente sem comprometer a capacidade das gerações futuras de atender as suas próprias necessidades". ${ }^{21}$

Nota-se que o conceito de desenvolvimento sustentável surgiu como forma de harmonizar os princípios dos direitos humanos com os princípios de proteção ambiental. A esse propósito, a Declaração do Rio, de 1992, e a Agenda 21 proclamaram o desenvolvimento sustentável como um direito humano, demonstrando a conexão entre a proteção ambiental e o respeito aos direitos fundamentais. A preocupação entre desenvolvimento econômico e o respeito ao meio ambiente ligou a maior parte dos movimentos sociais e ambientais que lutavam pelo respeito aos direitos humanos. ${ }^{22}$ Desde então, a proteção dos direitos humanos e do meio ambiente, ligado à sustentabilidade e ao desenvolvimento sustentável, constituem prioridades da agenda internacional.

Embora os domínios da proteção do ser humano e da proteção ambiental tenham sido tratados separadamente, é necessário buscar uma união entre eles, porquanto envolvem os rumos e destinos do gênero humano. A proteção do ser humano e ambiental é documentada pela agenda internacional, apresentada na Conferência das Nações Unidas sobre Meio Ambiente e Desenvolvimento, no Rio de Janeiro, em 1992, e na Conferência Mundial das Nações Unidas sobre

${ }^{21}$ GRIMONE, Marcos Ângelo. O conceito jurídico de direito sustentável no Brasil. Curitiba: Juruá, 2011, p. 59.

${ }^{22}$ GRIMONE, 2011, p. 59-60. 
Direitos Humanos, em Viena, em 1993. ${ }^{23}$ Desse modo, o domínio de proteção de ambos fortalece o amparo do ser humano e da humanidade, quando se trata da melhoria das condições de vida.

No âmbito global, a Declaração do Rio-92 e a Agenda 21, adotadas pela Conferência das Nações Unidas sobre Meio Ambiente e Desenvolvimento, contém, ambas, elementos próprios ao direito internacional dos direitos humanos e comuns dos domínios de amparo do ser humano e do meio ambiente. ${ }^{24}$ Significa que a Declaração do Rio-92 e a Agenda 21, visam à proteção dos seres humanos e ao atendimento das necessidades básicas em prol do desenvolvimento sustentável, assim como existe uma relação entre os direitos humanos e a sustentabilidade.

O direito humano à proteção ambiental abrange direitos explícitos e implícitos e visa a amparar o meio ambiente, a vida humana e a dignidade, como também expressa e reconhece como direito as necessidades humanas. Entretanto, existem limitações para alcançar um amparo ambiental adequado em nível mundial. Isso acontece, primeiramente, porque os direitos humanos não alcançam níveis de efetividade para a maioria da população mundial e, em segundo lugar, porque os direitos humanos tratam os graves e urgentes problemas ambientais de forma ineficaz e isolada, tanto em âmbito local, como regional e nacional. ${ }^{25}$

Ainda, existem dificuldades na relação entre direitos humanos e meio ambiente sustentável. Além disso, persistem controvérsias no direito ambiental internacional a respeito da concretização do direito humano ao meio ambiente ecologicamente equilibrado e saudável. 0 direito internacional ainda não reconhece o direito humano ao meio ambiente devido à soberania dos Estados e ao fato de as questões ambientais pertencerem ao domínio reservado da jurisdição dos Estados. ${ }^{26}$

Todavia, não há como negar que o direito ao meio ambiente saudável é fundamental à própria consagração dos direitos humanos, pois condiciona o direito à existência. Conforme afirma Bachelet, "a dignidade e o bem estar são [...] dois elementos gerados pelo ambiente, a que o ser humano tem um direito fundamental, tal como reconhece a Declaração de Estocolmo de 1972". ${ }^{27}$ Para tanto, não se pode desincumbir nenhuma instituição ou ator social. A proteção da dignidade humana e a melhoria do bem-estar do indivíduo incumbem tanto ao Estado como

\footnotetext{
${ }^{23}$ TRINDADE, Antônio Augusto Cançado. Direitos humanos e meio ambiente: paralelo dos sistemas de proteção internacional. Porto Alegre: Sergio Antonio Fabris, 1993, p. 23.

24 TRINDADE, 1993, p. 34.

${ }^{25}$ CARVALHO, Edson Ferreira de. Meio ambiente e direitos humanos. 2. ed. Curitiba: Juruá, 2011, p. 190.

${ }^{26}$ CARVALHO, 2011, p. 189-191.

${ }^{27}$ BACHELET, 1995, p. 71.
} 
aos cidadãos ou sociedade. Há reciprocidade e responsabilidade de todos em relação aos deveres e direitos em matéria ambiental.

Há uma dicotomia a ser resolvida referente ao caráter antropocêntrico dos direitos humanos em conflito com o caráter ecocêntrico no direito ambiental. Não é possível dotar as questões ambientais da condição de elevação, deixando o ente humano num plano inferior. Também, não se pode imaginar a centralidade do indivíduo sob uma perspectiva de preferência ou exclusividade por conta dos direitos humanos. Ao se admitir uma concepção antropocêntrica, inerente aos direitos humanos, priva-se o ambiente de uma proteção direta, porque o amparo à vida, à saúde e ao bem-estar humano seriam os objetivos da proteção ambiental, e os seres humanos são os únicos beneficiários da não violação do direito humano ao ambiente. ${ }^{28}$

Por outro lado, a efetivação do direito humano ao ambiente encontra na comunidade ambientalista suporte ao reconhecimento do valor intrínseco da natureza. Os ambientalistas entendem que "o meio ambiente deve ser protegido de outra maneira, mas não pela implementação do direito humano ao meio ambiente". ${ }^{29}$ Essa visão nega a proteção dos direitos humanos em relação ao indivíduo, porquanto se deve garantir o direito aos outros seres vivos. Eles alegam que o enfoque antropocêntrico “ignora os interesses de outras espécies e o equilíbrio ecológico mundial, além de encorajar a superexploração dos recursos naturais em prejuízo do ambiente como um todo". 30

Desse modo, “o objeto da proteção ecológica é toda a biosfera, a parte do universo onde situam todas as formas de vida, não constituindo os humanos mais do que uma das categorias de atores entre outras, que têm". ${ }^{31}$ Existe, portanto, uma estreita dependência entre a vida humana, a vida de todos os seres vivos e o equilíbrio do ambiente natural.

As questões ambientais constituem um elemento importante dos direitos básicos do ser humano: conforme certifica Freeland, "o meio ambiente não é uma abstração, pois representa o espaço vital, a qualidade de vida e a própria saúde dos seres humanos, inclusive das gerações ainda por vir". ${ }^{32}$ Dito de outro modo, os direitos ambientais representam um componente importante dos direitos humanos fundamentais, porque, sem acesso a um ambiente

${ }^{28}$ CARVALHO, 2011, p. 525.

${ }^{29}$ CARVALHO, 2011, p. 191.

${ }^{30}$ CARVALHO, 2011, p. 191.

${ }^{31}$ BACHELET, 1995, p. 71.

32 FREELAND, Steven. Direitos humanos, meio ambiente e conflitos: enfrentando os crimes ambientais. Revista SUR - Revista Internacional de Direitos Humanos. a. 2, n. 2, p. 118-145, 2005. Disponível em: <http://www.scielo.br/pdf/sur/v2n2/a06v2n2.pdf>. Acesso em: 20 mar. 2014, p. 119. 
sadio e equilibrado, as populações humanas não podem sobreviver. ${ }^{33} 0$ direito humano fundamental de viver em um ambiente saudável e equilibrado requer a proteção e a garantia jurídica do Estado e da coletividade.

A Convenção do Meio Ambiente Humano, de 1972, realizada em Estocolmo, na Suécia, estabeleceu que o ser humano tem o direito fundamental a [...] um ambiente de uma qualidade tal que lhe permita levar uma vida digna, gozar de bem estar [...]. A Convenção Americana dos Direitos Humanos, no âmbito dos direitos econômicos, sociais e culturais afirmou o direito a viver em um ambiente saudável, direito que foi inscrito nas constituições nacionais de muitos países. 34

Por conseguinte, a proteção ao meio ambiente deve ser considerada como caminho para se conseguir o cumprimento dos direitos humanos, de forma que o dano praticado ao ambiente importará lesão aos direitos fundamentais, na medida em que afeta diretamente o direito à vida - com dignidade - à saúde, à igualdade e ao bem-estar. É fundamental que haja interligação em prol de interesse comum: a proteção ambiental e a elevação dos direitos humanos buscam a sustentabilidade como forma de combater a miséria ante a ameaça à vida no planeta.

\section{A RELAÇÃO ENTRE OS DIREITOS HUMANOS, O MEIO AMBIENTE E O DESENVOLVIMENTO}

A preocupação com a questão ecológica e/ou ambiental se desenvolveu a partir da Declaração sobre o Direito ao Desenvolvimento das Nações Unidas, de 1986. Esse documento destaca o ente humano como "sujeito central do desenvolvimento", devendo, a um só tempo, "ser participante ativo e (seu) beneficiário". Ademais, "qualifica o direito ao desenvolvimento como um direito humano inalienável de toda pessoa humana e todos os povos". ${ }^{35}$

Entretanto, o desenvolvimento como um direito humano já havia sido reconhecido anteriormente por meio da Carta Africana de Direitos Humanos e dos Povos, de 1981, com a assertiva de que "todos os povos têm direito ao seu desenvolvimento econômico, social e cultural, no estrito respeito da sua liberdade e da sua identidade, e ao gozo igual do patrimônio

\footnotetext{
${ }^{33}$ FREELAND, 2014, p. 119.

${ }^{34}$ FREELAND, 2014, p. 119.

${ }^{35}$ TRINDADE, 1993, p. 173.
} 
comum da humanidade". ${ }^{36}$ A rigor, a Declaração de 1986 instituiu princípios para que todos os direitos humanos e liberdades fundamentais possam ser plenamente realizados.

O desenvolvimento é um processo de expansão das liberdades humanas, sendo, ao mesmo tempo, o principal fim e meio. ${ }^{37} 0$ valor intrínseco da liberdade humana consiste, portanto, no fim supremo do desenvolvimento.

O fundamento do direito humano ao meio ambiente ecologicamente equilibrado é a dignidade humana. Consiste na necessidade de se manter o ambiente em condições de assegurar a sobrevivência da espécie humana e de outros seres vivos com qualidade e proveito. O gozo da pauta dos direitos humanos reconhecidos internacionalmente depende, intrinsecamente, da ligação com o meio ambiente, observando-se que, do ponto de vista biológico, a dependência do ser humano em relação ao ambiente é integral.

De acordo com Carvalho, "a relação entre direitos humanos e proteção ambiental é evidente, pois sem um meio ambiente saudável ou ecologicamente equilibrado não se pode gozar dos básicos direitos reconhecidos pela Declaração Universal dos Direitos Humanos". ${ }^{38}$ A relação entre ambos mostra a necessidade de se promover a proteção do meio ambiente e o pleno gozo de todos os direitos humanos. É indispensável a relação entre direitos humanos, proteção ambiental e desenvolvimento. “A preocupação com a protecção dos direitos humanos e a preocupação com a protecção do ambiente reforçam-se mutuamente". ${ }^{39}$ Os direitos humanos e o direito do ambiente são necessários para garantir melhores condições de vida às populações.

Os direitos humanos e o ambiente estão intrinsecamente ligados. Sem os direitos humanos, a protecção ambiental não poderia ser realmente executada. E, viceversa: sem a inclusão do ambiente, os direitos humanos estariam em perigo de perder a sua função essencial, que é a protecção da vida humana, do bem-estar e da integridade. ${ }^{40}$

Noutro aspecto, como resultado de conquistas históricas, não se pode deixar de reconhecer que os direitos humanos estão se dilatando cada vez mais, na mesma medida em que

${ }^{36}$ TRINDADE, 1993, p. 184.

37 SEN, Amartya. Desenvolvimento como liberdade. Tradução de Laura Teixeira Motta. São Paulo: Companhia das Letras, 2010, p. 10.

${ }^{38}$ CARVALHO, 2011, p. 156.

${ }^{39}$ BOSSELMANN, Klaus. Direitos humanos, ambiente e sustentabilidade. RevCEDOUA - Revista do Centro de Estudos de Direito do Ordenamento, do Urbanismo e do Ambiente. n. 21, v. 11, p. 9-38, nov., 2008, p. 9. Disponível em: <https://digitalis-dsp.uc.pt/bitstream/10316.2/8821/3/1.pdf?ln=pt-pt>. Acesso em: 28 mai 2015.

${ }^{40}$ BOSSELMANN, 2008, p. 23. 
demandas passadas já foram superadas, exigindo-se, igualmente, a ampliação dos instrumentos para suas proteções. ${ }^{41}$ Desse modo, é importante enfatizar que o direito a um meio ambiente sadio e equilibrado com a qualidade de vida é algo que integra a pauta atual.

\subsection{Dano ambiental: violação de direitos humanos}

Os direitos humanos integrou o meio ambiente sadio como um direito humano, em 1970, quando percebeu a relação entre poluição, degradação ambiental e violação dos direitos humanos. Em 1972, a Declaração de Estocolmo sobre o Ambiente Humano, decorrente da Conferência das Nações Unidas sobre o Meio Ambiente, enfatizou, no Princípio 1, que a preservação do meio ambiente é essencial para o gozo dos direitos humanos. A Declaração de Estocolmo foi o primeiro documento internacional a assegurar a relação entre preservação do meio ambiente e realização dos direitos humanos. Já a Declaração do Rio sobre Meio Ambiente e Desenvolvimento, da Conferência das Nações Unidas sobre Meio Ambiente e Desenvolvimento de 1992, adotou um entendimento distinto daquela disposta na Declaração de Estocolmo, pois enfatizou, no Princípio 10, que o exercício de determinados direitos humanos são essenciais para a proteção do meio ambiente. ${ }^{42}$

No entanto, após a Conferência de Estocolmo de 1972 e o aparecimento do relatório Brundtland em 1987, não houve progressos significativos em direção ao direito humano ao ambiente. Em contraste com o Princípio 1 da Declaração de Estocolmo de 1972, o Princípio 1 da Declaração do Rio de 1992, afirma que "os seres humanos estão no centro das preocupações relativamente ao desenvolvimento sustentável. Eles têm o direito a uma vida saudável e produtiva em harmonia com a natureza". ${ }^{43}$

\footnotetext{
41 "Os direitos humanos são universais e, cada vez mais, se projetam no sentido de seu alargamento objetivo e subjetivo, mantendo seu caráter de temporalidade - não temporariedade. Sendo, portanto, históricos, não definitivos, exigindo a todo o instante não apenas o reconhecimento de situações novas, como também a moldagem de novos instrumentos de resguardo e efetivação". MORAIS, Jose Luis Bolzan de. As crises do Estado e da Constituição e a transformação espaço-temporal dos direitos humanos. 2. ed. Porto Alegre: Livraria do Advogado, 2011, p. 86.

42 SPIELER, Paula; MELO, Carolina de Campos; CUNHA, José Ricardo. Direitos humanos. Rio de Janeiro: FGV, 2010, p. 183.

${ }^{43}$ BOSSELMANN, 2008, p. 19.
} 
Sobre a garantia dos direitos humanos, Bobbio afirma que "o mais importante deles é o reivindicado pelos movimentos ecológicos: o direito de viver num ambiente não poluído". ${ }^{44} 0$ direito humano a um ambiente saudável foi formulado no Princípio 1 da Declaração de Estocolmo de 1972: "O homem tem o direito fundamental à liberdade, à igualdade e a condições adequadas de vida num ambiente de qualidade que permita uma vida com dignidade e bem-estar, e tem a responsabilidade solene de proteger e melhorar o ambiente para as gerações presentes e futuras". 45

Segundo Bosselmann, os direitos humanos podem ser usados para combater indiretamente o dano, a degradação e a poluição ambiental, que constituem uma ameaça aos direitos humanos, como também, podem ser usados para garantir diretamente a proteção do ambiente e assegurar o direito humano a um ambiente saudável. ${ }^{46}$ Porquanto, sempre que ocorrer dano, degradação e poluição ambiental, ocorre violação do gozo de direitos humanos. 0 ambiente não deve ser deteriorado e colocar gravemente em perigo o direito à vida, o direito à saúde e ao bem-estar. “A protecção do ambiente é [...] uma parte vital da doutrina actual dos direitos humanos, na medida em que é um sine qua non para vários direitos humanos, nomeadamente o direito à saúde e o direito à própria vida". ${ }^{47} \mathrm{O}$ dano, a degradação e a poluição ao ambiente podem colocar em perigo todos os direitos humanos de que trata a Declaração Universal dos Direitos Humanos, de 1948.

Dessa forma, verifica-se que a proteção do meio ambiente consiste na garantia dos direitos humanos, pois, havendo dano ao ambiente, consequentemente, haverá lesão aos direitos fundamentais. Cabe ressaltar então que, a partir da Declaração Universal dos Direitos Humanos, de 1948, os direitos humanos passaram a ser assinalados pela "universalidade e indivisibilidade", assim compreendidos:

Universalidade porque clama pela extensão universal dos direitos humanos, sob a crença de que a condição de pessoa é o requisito único para a titularidade de direitos, considerando o ser humano como um ser essencialmente moral, dotado de unicidade existencial e dignidade. Indivisibilidade porque a garantia dos direitos civis e políticos é condição para a observância dos direitos sociais, econômicos e culturais. [...] Os direitos humanos compõem, assim, uma unidade

\footnotetext{
${ }^{44}$ BOBBIO, Norberto. A era dos direitos. Tradução de Carlos Nelson Coutinho. Rio de Janeiro: Elsevier, 2004, p. 5.

${ }^{45}$ BOSSELMANN, 2008, p. 18.

${ }^{46}$ BOSSELMANN, 2008, p. 10-11.

${ }^{47}$ BOSSELMANN, 2008, p. 12.
} 
indivisível, interdependente e inter-relacionada, capaz de conjugar o catálogo de direitos civis e políticos, ao catálogo de direitos sociais, econômicos e culturais. 48

Sendo possuidores do status de universais e indivisíveis, os direitos humanos adquirem, também, o caráter de fundamentais, porque essenciais à existência humana e à capacidade de desenvolver e de participar plenamente da vida. Portanto, os direitos humanos representam as condições mínimas necessárias para uma vida digna, ${ }^{49}$ como também a imprescindibilidade de proteção ao ambiente sadio e ecologicamente equilibrado.

O desenvolvimento do Direito Internacional dos Direitos Humanos deu-se com a “aprovação da Declaração Universal dos Direitos do Homem de 1948, que logo cogitou de adotar inúmeros tratados internacionais voltados à proteção de direitos fundamentais", ${ }^{50}$ assim como vários instrumentos internacionais voltados à proteção do homem.

A integração entre os direitos humanos e o meio ambiente ocorreu posteriormente, com a Declaração de Direitos Humanos de Viena, de 1993. Esse documento reitera o conteúdo da Declaração de 1948, confirmando "a universalidade dos direitos humanos, reconhecendo como interdependentes e inter-relacionados, devendo ser tratados globalmente de forma justa e equitativa, em pé de igualdade e com a mesma ênfase".

A Declaração de Direitos Humanos de Viena afirmou que o desenvolvimento é um direito universal e inalienável, bem como ressaltou a interdependência entre os direitos humanos e o desenvolvimento. ${ }^{51}$ A percepção integrativa dos direitos humanos com a questão ambiental, no documento de Viena, é assinalada, conforme destaca Santos:

A II Conferência Mundial de Direitos Humanos, de 1993, em Viena, sedimentou em caráter universal a necessidade de preservação dos direitos humanos e, reafirmou o compromisso e responsabilidade de todos os Estados de promover o respeito universal e proteção de todos os direitos humanos e, o direito ao desenvolvimento como parte integrante dos direitos humanos universais, bem como propugnou pela cooperação dos Estados com as ONGs para garantia efetiva dos direitos humanos, definiu a extrema pobreza como inibidora do pleno

48 PIOVESAN, Flávia (coord.). Direitos humanos: desafios da ordem internacional contemporânea. In: PIOVESAN, Flávia (coord.). Direitos humanos. V. 1. Curitiba: Juruá, 2006, p. 18.

${ }^{49}$ GORCZEVSKI, Clovis. Direitos humanos: dos primórdios da humanidade ao Brasil de hoje. Porto Alegre: Imprensa Livre, 2005, p. 17.

50 PIOVESAN, Flávia. Temas de direitos humanos. São Paulo: Max Limonad, 1998, p. 30.

${ }^{51}$ PIOVESAN, 2006, p. 19. 
exercício dos direitos humanos e, propôs que o desenvolvimento deve satisfazer as necessidades ambientais para garantir a sobrevivência das gerações futuras. 52

No mesmo enfoque, Trindade afirma que os direitos humanos ganharam muito mais sentido a partir desse documento, pela integração dos direitos essenciais com o direito ao "meio ambiente, do apoio às democracias e à diversidade cultural". ${ }^{53}$

A pós-modernidade não conseguiu superar os compromissos do desenvolvimento sustentável, como as desigualdades e as privações sociais, ambientais e econômicas. Os problemas vão sendo acumulados na medida em que não se conseguiu sanar as antigas demandas. A sociedade atual convive com questões antigas e que não só perduram como se renovam a cada período, ante "a persistência da pobreza e de necessidades essenciais não satisfeitas, fomes coletivas e fome crônica muito disseminada, [...] ameaças cada vez mais graves ao nosso meio ambiente e à sustentabilidade de nossa vida econômica e social". ${ }^{54}$

A busca pela sustentabilidade significa conseguir um desenvolvimento saudável, com responsabilidade, de modo a ampliar a satisfação de liberdades, como o atendimento aos bens sociais básicos, a qualidade do meio ambiente e sadia qualidade de vida. ${ }^{55}$ Como ressaltado, há uma ligação entre o meio ambiente, os direitos humanos e o desenvolvimento, pois essa vinculação pressupõe a proteção à vida dos seres humanos e a garantia do exercício de outros direitos e liberdades fundamentais. ${ }^{56}$

Portanto, proteger o meio ambiente e o ser humano são os objetivos do desenvolvimento baseado na sustentabilidade. A relação entre os direitos humanos, a sustentabilidade e o desenvolvimento evidencia a necessidade de se promover o pleno gozo de todos os direitos humanos e fundamentais. Somente assim poder-se-á atingir o mínimo desejável de justiça social, qualidade de vida, equilíbrio ambiental e desenvolvimento sustentável na esfera global.

52 SANTOS, Antônio Silveira R. dos. Direitos humanos e meio ambiente. Jus Navigandi, Teresina, a. 5, n. 46, out. 2000. Disponível em: <http://jus.com.br/artigos/1684>. Acesso em: 15 mar. 2014, [s. p.].

${ }^{53}$ TRINDADE, 1993, p. 271.

${ }^{54}$ SEN, 2010, p. 9.

55 CARVALHO, Sonia Aparecida de. A justiça ambiental como instrumento de garantia dos direitos fundamentais sociais e ambientais no Estado transnacional. Revista Eletrônica Direito e Política, Univali, Itajaí-SC, v. 8, n. 2, p. 981-1004, maio/ago., 2013. Disponível em: $<$ www.univali.br/direitoepolitica>. Acesso em: 20 mar. 2014, p. 988.

56 CARVALHO, Sonia Aparecida de. 0 direito ao desenvolvimento sustentável como direito humano fundamental. In: GORCZEVSKI, Clovis (org.). Direitos humanos e participação política. V. IV. Porto Alegre: Imprensa Livre, 2013, p. 239. 


\section{CONCLUSÃO}

A hegemonia do modelo econômico, regulado pelo neoliberalismo rumo a um crescimento desregulado sem que haja restrições à livre iniciativa e ao poder do capital, principalmente, nas três últimas décadas, tem causado danos graves ao meio ambiente e violações aos direitos humanos, empurrando as populações fragilizadas à situação de miséria para espaços ambientais extremamente agredidos e degradados.

Antigamente, pensava-se que a necessidade de desenvolvimento implicava na contradição da preocupação com a preservação e conservação do meio ambiente e dos bens naturais; atualmente, esse pensamento é desmitificado não somente pela necessidade de convivência, como pela percepção da harmonia entre essas demandas. Porém, a pretensão econômica e o descompromisso com valores essenciais para a própria existência da vida no planeta atropelam a busca de um futuro da sustentabilidade.

Existem questões relevantes no que tange ao desenvolvimento sustentável, como a implantação de instrumentos que viabilizem o amparo não somente dos direitos humanos como da eficaz proteção ao meio ambiente, buscando a sustentabilidade e o equilíbrio no crescimento econômico e social.

O modelo neoliberal modernizou e acelerou o modo e a circulação do capital, porém, a economia dominante tornou os Estados e as populações dependentes do capitalismo e do crescimento econômico. Esse crescimento econômico acelerado, decorrente dos impulsos de mais lucros ao capital, causa consequências trágicas para toda a economia globalizada, trazendo implicações drásticas, principalmente, às populações mais pobres, com enormes impactos ambientais, e aos direitos humanos.

A independência e soberania dos Estados foram restringidas pelo neoliberalismo que estabeleceu os rumos da economia mundial e impôs restrições e condições aos países, sobretudo, àqueles em desenvolvimento ou subdesenvolvidos, causando violação aos direitos humanos e agressão ao meio ambiente. A diminuição da atuação do Estado reduz a capacidade de garantir e satisfazer as necessidades básicas da população na moderação das desigualdades sociais e no atendimento dos direitos fundamentais. 
É necessário o comprometimento da comunidade internacional num novo modelo de governança, com maior regulação e controle dos mercados. Na esfera internacional, é necessário estabelecer regras e limitações ao setor financeiro, criando uma agenda proativa em favor das questões ambientais e dos direitos humanos. Esses assuntos não se limitam a determinado governo ou posições ideológicas, mas vinculam-se a questões que afetam toda a humanidade, sob pena de agravarem os problemas ambientais e humanitários com o aumento das desigualdades sociais, da pobreza extrema de parcela da população e da riqueza absoluta e desmedida de grupos cada vez mais restritos.

Portanto, o direito ao meio ambiente ecologicamente equilibrado e saudável integra o rol dos direitos humanos, consistindo na proteção da dignidade humana e na necessidade de se manter o ambiente em condições de assegurar a sobrevivência da espécie humana e a realização dos demais direitos. Nesse aspecto, há uma relação intrínseca entre os direitos humanos, a o desenvolvimento sustentável e a sustentabilidade.

\section{REFERÊNCIAS}

BACHELET, Michel. Ingerência ecológica: direito ambiental em questão. Tradução de Fernanda Oliveira. Lisboa: Instituto Piaget, 1995.

BOBBIO, Norberto. A era dos direitos. Tradução de Carlos Nelson Coutinho. Rio de Janeiro: Elsevier, 2004.

BOSSELMANN, Klaus. Direitos humanos, meio ambiente e sustentabilidade. In: SARLET, Ingo Wolfgang (org.); KRELL, Andreas J. et al. Estado socioambiental e direitos fundamentais. Porto Alegre: Livraria do Advogado, 2010, p. 73-109.

Direitos humanos, ambiente e sustentabilidade. RevCEDOUA - Revista do Centro de Estudos de Direito do Ordenamento, do Urbanismo e do Ambiente. n. 21, v. 11, p. 9-38, nov., 2008. Disponível em: <https://digitalis-dsp.uc.pt/bitstream/10316.2/8821/3/1.pdf?ln=pt-pt>. Acesso em: 28 mai 2015.

CARVALHO, Edson Ferreira de. Meio ambiente e direitos humanos. 2. ed. Curitiba: Juruá, 2011.

CARVALHO, Sonia Aparecida de. A justiça ambiental como instrumento de garantia dos direitos fundamentais sociais e ambientais no Estado transnacional. Revista Eletrônica Direito e Política, Univali, Itajaí-SC, v. 8, n. 2, p. 981-1004, maio/ago., 2013. Disponível em: <www.univali.br/direitoepolitica>. Acesso em: 20 mar. 2014. 
- O direito ao desenvolvimento sustentável como direito humano fundamental. In: GORCZEVSKI, Clovis (org.). Direitos humanos e participação política. V. IV. Porto Alegre: Imprensa Livre, 2013, p. 215-241.

CRUZ, Paulo Márcio; BODNAR, Zenildo (orgs.). Globalização, transnacionalidade e sustentabilidade. Itajaí: Univali, 2012. Disponível em: <http://www.univali.br/ppcj/ebook>. Acesso em: 5 maio 2013.

. Globalização, transnacionalidade e sustentabilidade. Itajaí: Univali, 2012. E-book. Disponível em: <http://siaiapp28.univali.br/LstFree.aspx>. Acesso em: 10 jul. 2014.

FREELAND, Steven. Direitos humanos, meio ambiente e conflitos: enfrentando os crimes ambientais. Revista SUR - Revista Internacional de Direitos Humanos. a. 2, n. 2, p. 118-145, 2005. Disponível em: <http://www.scielo.br/pdf/sur/v2n2/a06v2n2.pdf>. Acesso em: 20 mar. 2014.

FREITAS, Juarez. Sustentabilidade: direito ao futuro. 2. ed. Belo Horizonte: Fórum, 2012.

GORCZEVSKI, Clovis. Direitos humanos: dos primórdios da humanidade ao Brasil de hoje. Porto Alegre: Imprensa Livre, 2005.

GRIMONE, Marcos Ângelo. O conceito jurídico de direito sustentável no Brasil. Curitiba: Juruá, 2011.

LEFF, Enrique. Discursos sustentáveis. Tradução de Silvana Cobucci Leite. São Paulo: Cortez, 2010.

Saber ambiental: sustentabilidade, racionalidade, complexidade, poder. Tradução de Lúcia Mathilde Endlich Orth. 8. ed. Petrópolis: Vozes, 2011.

MORAIS, Jose Luis Bolzan de. As crises do Estado e da Constituição e a transformação espaçotemporal dos direitos humanos. 2. ed. Porto Alegre: Livraria do Advogado, 2011.

PIOVESAN, Flávia (Coord.). Direitos humanos: desafios da ordem internacional contemporânea. In: PIOVESAN, Flávia (coord.). Direitos humanos. V. 1. Curitiba: Juruá, 2006, p. 15-37.

. Temas de direitos humanos. São Paulo: Max Limonad, 1998.

RIECHMANN, Jorge; REYES, Luis González; HERRERO, Yayo; MADORRÁN, Carmen (orgs.). Qué hacemos hoy cuando nos encontramos frente a la amenaza de uma crisis mayor que la económica: la ecológica. Madrid: Ediciones Akal, S. A., 2012.

SACHS, Ignacy. Caminhos para o desenvolvimento sustentável. Organização de Paula Yone Stroh. Rio de Janeiro: Garamond, 2002.

. Caminhos para o desenvolvimento sustentável. Tradução de José Lins Albuquerque Filho. Organização de Paula Yone Stroh. Rio de Janeiro: Garamond, 2009. 
SANTOS, Antônio Silveira R. dos. Direitos humanos e meio ambiente. Jus Navigandi, Teresina, a. 5, n. 46, out. 2000. Disponível em: <http://jus.com.br/artigos/1684>. Acesso em: 15 mar. 2014, [s. p.].

SEN, Amartya. Desenvolvimento como liberdade. Tradução de Laura Teixeira Motta. São Paulo: Companhia das Letras, 2010.

SOARES, Josemar. A dimensão ético-existencial da sustentabilidade. In: XXI Encontro Nacional do CONPEDI, 2012, Uberlândia. Anais do XXI Encontro Nacional do CONPEDI. Florianópolis: Fundação Boiteux, 2012, p. 5068-5108. Disponível em: <http://www.publicadireito.com.br/artigos/?cod=d523773c6b194f37>. Acesso em: 20 jul. 2014.

SPIELER, Paula; MELO, Carolina de Campos; CUNHA, José Ricardo. Direitos humanos. Rio de Janeiro: FGV, 2010.

TRINDADE, Antônio Augusto Cançado. Direitos humanos e meio ambiente: paralelo dos sistemas de proteção internacional. Porto Alegre: Sergio Antonio Fabris, 1993.

Recebido em: 02/09/2014 Revisado em: 20/12/2014 e 11/05/2015 / Aprovado em: 18/09/2015 